\title{
Impulse control disorders in Parkinson's disease
}

\author{
Mark Stacy
}

Address: Duke University Medical Center, 932 Morreene Road, MS 3333, Durham, NC 27705, USA

Email: mark.stacy@duke.edu

Fl000 Medicine Reports 2009, I:29 (doi: 10.34I0/MI-29)

The electronic version of this article is the complete one and can be found at: http://www.FI000.com/Reports/Medicine/content/I/29

\begin{abstract}
Since the original descriptions of hedonistic homeostatic dysregulation syndrome and pathological gambling in Parkinson's disease, impulse control disorders, such as compulsive spending, punding, or binge eating, are increasingly recognized. Although the term hedonistic homeostatic dysregulation syndrome has been supplanted by the concept of the dopamine dysregulation syndrome, the features of severe dyskinesias, cyclical mood disorder with hypomania or manic psychosis, and impairment of social and occupational functioning in the setting of increased intake of antiparkinson therapy remain. At this time, impulse control disorder is defined as maladaptive behaviors that emerge with disease progression and increasing antiparkinson medications. These behaviors may be disruptive, such as punding, or destructive, such as compulsive spending, gambling, binge eating, or hypersexuality.
\end{abstract}

\section{Introduction and context}

It has long been recognized that treatment of the motor symptoms of Parkinson's disease (PD) with dopamine replacement therapy (DRT) may be associated with psychiatric disturbances [1]. Additional behaviors, characterized by impulsivity and/or compulsivity, include pathological gambling, hypersexuality, compulsive shopping, binge eating, punding, and overuse of DRT [2-8]. In addition, overuse of DRT has been referred to as homeostatic hedonistic dysregulation (HHD) or dopamine dysregulation syndrome (DDS) $[9,10]$. In DDS/ HHD, patients inappropriately consume more dopaminergic medication than is required to adequately control motor symptoms and often experience significant disruption of social and employment activities [11].

Whereas disruptive or compulsive behaviors appear to be linked to levodopa replacement therapy, destructive behaviors are more often associated with behavioral addiction, predominantly in PD patients using dopamine agonists $[8,12]$. Features associated with these behaviors include early age of onset, longer duration of disease, family history of psychiatric disorders, depression, or prior history of gambling. The majority of reports indicate that the onset of these behaviors is associated with the use of dopamine agonists either as monotherapy or in addition to levodopa rather than with the use of levodopa alone. Patients with binge eating disorder usually have other behavioral addictions, including pathological gambling, compulsive shopping, hypersexuality, and punding, as well as a history of weight control issues [5]. The abnormal behaviors of hypersexuality range from markedly increased sexual drive to rare reports of paraphilia [8]. These symptoms appear to be more common in men with early-onset PD. Unlike other destructive behaviors, hypersexuality has been associated with levodopa, dopamine agonists or selegiline, and a history of alcohol or tobacco addiction [8].

\section{Recent advances}

\section{Phenomenology: impulse control disorders}

The true prevalence of impulse control disorder (ICD) has yet to be defined, but the development of these symptoms is correlated with age, disease duration, a prior history of depression or drug abuse, and a number of other factors (Table 1). Screening of 272 consecutive PD patients revealed a prevalence rate for pathological gambling, hypersexuality, or compulsive shopping of $4 \%$ and a lifetime prevalence rate of 6.6 to $9.1 \%[13,14]$. However, the DOMINION study (Impulse Control 
Table I. Risk factors for impulse control disorders (ICD) [23]

\begin{tabular}{|c|c|c|}
\hline Risk factors for ICD & Possible ICDs & Definite ICDs \\
\hline $\begin{array}{l}\text { Diagnosis prior to } 50 \text { years of age } \\
\text { Diagnosed for }>5 \text { years } \\
\text { Male gender } \\
\text { History of depression, anxiety, or bipolar disorder } \\
\text { Prior drug/alcohol abuse } \\
\text { Prior gambling or other behavioral addiction } \\
\text { Family history of mental illness } \\
\text { Family history of drug/alcohol addiction } \\
\text { Dyskinesias } \\
\text { Levodopa or equivalent dopaminergic therapy dosages }>1,000 \mathrm{mg} / \text { day } \\
\text { Dopamine agonist therapy }\end{array}$ & $\begin{array}{l}\text { Reported change in personality or behavior } \\
\text { Increased secrecy } \\
\text { Increased time at hobbies or work } \\
\text { Decreasing need for sleep or complaints } \\
\text { of insomnia } \\
\text { Increased medication intake } \\
\text { Hoarding medications }\end{array}$ & $\begin{array}{l}\text { Compulsive behavior (punding) } \\
\text { >I hour/day } \\
\text { Addictive behavior: } \\
\text { Gambling } \\
\text { Shopping } \\
\text { Increased libido } \\
\text { Hypersexual behavior } \\
\text { Binge eating }\end{array}$ \\
\hline
\end{tabular}

ICD, impulse control disorder.

Disorders in Parkinson's Patients Treated With Pramipexole and Other Agents), a prospective multi-centered trial to assess the frequency of these behaviors in more than 3,000 subjects, has found that at least one ICD was identified in $13.6 \%$ of patients, while $4.9 \%$ of patients had multiple behaviors. The frequencies of single ICDs reported for the entire population were: compulsive buying $(5.7 \%)$, compulsive gambling $(5.0 \%)$, bingeeating disorder (4.3\%), and compulsive sexual behavior $(3.5 \%)[15]$.

Although the majority of the reports note an association of these behaviors with the use of dopamine agonists, some cases do occur in patients on levodopa alone. It has also been argued that ICD behaviors may be independent of DRT and secondary to disease severity and progression $[8,13,14]$.

\section{Dopamine dysregulation syndrome}

Approximately $4 \%$ of PD patients on DRT are reported to overuse dopaminergic medications. Compulsive medication dosing has been noted to be more prevalent in men $[14,16]$. In addition, a history of alcohol abuse, mood disorders, and family history of psychiatric problems may be predisposing factors. Diagnostic criteria have been proposed for DDS and include at least a 6-month history of the need for increased doses of DRT, pathological drug use, impairment in social or employment functions, affective disorders, and a withdrawal state when medications are decreased $[10,11]$. Some individuals with DDS meet diagnostic criteria for substance dependence $[13,14]$.

\section{Punding}

Punding refers to aimless repetitive activity often involving manipulations of a familiar object. The term is borrowed from the vernacular of Swedish intravenous amphetamine addicts exhibiting this behavior and is loosely translated as 'blockhead'. This behavior was first suggested as being levodopa-induced by Dr Joseph
Friedman. Now punding is defined as compulsive performance of repetitive tasks, such as assembly/ disassembly, collecting things, or sorting household objects [17-19]. Other behaviors, 'hobbyisms', that may represent variants of punding include excessive humming or singing, inordinate writing, paper shuffling, blogging/journaling, doodling, painting, walkabouts, and reciting long meaningless soliloquies without an audience. Interestingly, performance of these behaviors may be linked to increased synaptic dopamine, since amphetamine, cocaine, and levodopa share a presynaptic mechanism. In addition, these activities seem to be more prominent during 'on time' and 'on time with dyskinesias'. These repetitive behaviors are associated with high dosages of DRT (greater than 800 levodopa equivalents per day) and seem to occur in the 'on-state'.

\section{Pathogenesis}

The anatomic substrate for ICD is not fully elucidated. The direct pathway, mediated through D1 dopamine receptors, is associated with the development of motor symptoms of PD, such as wearing off and dyskinesias. The D2 dopamine receptor mediates neuronal activity in the indirect pathway and has a prominent role in ICD in $\mathrm{PD}$ and in addiction disorders [8]. Within the D2-type receptor family are D3 receptors, which reside within the ventral striatum/nucleus accumbens and modulate nonmotor circuits. These non-motor circuits include: the dorsolateral prefrontal cortex, regulating executive function; the lateral orbitofrontal cortex, modulating socially appropriate behavior and mood; and the anterior cingulate cortex, initiating activity and maintaining interest [20,21]. Given the homologies of binding sites between levodopa and amphetamine, receptor changes in PD may underlie the disruptive behaviors of DRTrelated compulsivity, similar to punding in addiction disorders. Destructive behaviors may arise in the continuum of neurodegeneration, levodopa-related changes, and the addition of variably selective D3/D2 dopamine agonists [8]. 
Recent outcomes

In July 2007, the first international meeting devoted to this topic was held in Toronto [22]. Nearly 100 clinicians and researchers from six countries met in this 2-day workshop to discuss a wide range of topics, including punding, behavioral addiction, addiction to DRT, and the seemingly paradoxical observations concerning the use of deep brain stimulation in this population. The faculty for the seven scientific sessions represented subspecialty interest in neurology, psychiatry, addiction, and neuroscience, and a poster session provided additional new information concerning this interesting behavioral syndrome. The major outcomes from this meeting were: (1) defining the clinical features of this syndrome [23], and (2) identifying an unmet need for validated clinical assessments in this population of PD patients [24].

\section{Implications for clinical practice}

Treatment of ICD requires early recognition of the symptoms. Because of the potential for these addictive symptoms to rapidly escalate, adequate and consistent patient education is important, particularly when introducing a new dopaminergic therapy or increasing the dosage of a dopaminergic agent. If any symptoms of ICD are recognized, inquiry for other symptoms is important because, for instance, symptoms of hypersexuality may require treatment strategies that differ to those of compulsive spending or punding $[8,25]$.

The initial intervention is usually a function of reducing the last medication changed in treating PD. In the initial reports of pathological gambling, the behaviors emerged after increasing dopamine agonist therapy. In the majority of these instances, reduction or discontinuation of this agent resulted in behavior benefit. In general, patients with compulsive gambling, spending, or eating usually respond to dopamine agonist reduction, whereas patients with punding benefit from levodopa reduction. The population with problems resulting from hyperhedonistic behaviors may benefit from reduction of either dopamine agonist or levodopa. Clearly, DDS requires careful reduction of dopaminergic therapy [25].

Additional treatment interventions are highly anecdotal but include treatment of comorbid depression with selective serotonin-reuptake inhibitor or other antidepressants or bipolar symptoms with lithium or antipsychotic agents, such as quetiapine or clozapine. Preliminary study with acamprosate, a synthetic structural analogue of the amino acid neurotransmitter gamma-aminobutyric acid (GABA) approved for the treatment of alcohol abuse, suggests that this agent may be helpful in treating compulsive eating and sweet craving. Counselling may be important in the setting of sexual, eating, or gambling addictions. Lay support groups for problem addictions (for example, Gamblers Anonymous) have been suggested frequently, because of additional advice regarding the financial options important in this recovery [25].

\section{Abbreviations}

DDS, dopamine dysregulation syndrome; DOMINION, Impulse Control Disorders in Parkinson's Patients Treated With Pramipexole and Other Agents; DRT, dopamine replacement therapy; GABA, gamma-aminobutyric acid; HHD, homeostatic hedonistic dysregulation; ICD, impulse control disorder; PD, Parkinson's disease.

\section{Competing interests}

The author has served as a consultant to GlaxoSmithKline (Uxbridge, Middlesex, UK) to provide advice for tools to monitor the development of impulse control disorder symptoms related to ropinirole and ropinirole XL. He also served on the steering committee for DOMINION, a trial sponsored by Boehringer-Ingelheim (Ingelheim, Germany), to assess the frequency of impulse control disorders in a Parkinson's disease population.

\section{References}

I. Goodwin FK: Psychiatric side effects of levodopa in man. JAMA 1971, 2 18:1915-20.

2. Driver-Dunckley E, Samanta J, Stacy M: Pathological gambling associated with dopamine agonist therapy in Parkinson's disease. Neurology 2003, 61 :422-3.

3. Dodd ML, Klos KJ, Bower JH, Geda YE, Josephs KA, Ahlskog JE: Pathological gambling caused by drugs used to treat Parkinson disease. Arch Neurol 2005, 62:|377-81.

FI000 Factor 3.0 Recommended Evaluated by Kent Berridge 26 Jul 05

4. Uitti RJ, Tanner CM, Rajput AH, Goetz CG, Klawans HL, Thiessen B: Hypersexuality with antiparkinsonian therapy. Clin Neuropharmacol 1989, I 2:375-83.

5. Nirenberg MJ, Waters C: Compulsive eating and weight gain related to dopamine agonist use. Mov Disord 2006, 21 :524-9.

6. Kurlan R: Disabling repetitive behaviors in Parkinson's disease. Mov Disord 2004, 19:433-7.

7. Pontone G, Williams JR, Bassett SS, Marsh L: Clinical features associated with impulse control disorders in Parkinson disease. Neurology 2006, 67:1258-6I.

8. Ferrara JM, Stacy M: Impulse control disorders and Parkinson's disease. CNS Spectr 2008, 13:690-8.

9. Giovannoni G, O'Sullivan JD, Turner K, Manson AJ, Lees AJ: Hedonistic homeostatic dysregulation in patients with Parkinson's disease on dopamine replacement therapies. J Neurol Neurosurg Psychiatry 2000, 68:423-8.

10. Evans $\mathrm{AH}$, Lees $\mathrm{A}$ : Dopamine dysregulation syndrome in Parkinson's disease. Curr Opin Neurol 2004, I 7:393-8.

II. Pezzella FR, Colosimo C, Vanacore N, Di Rezze S, Chianese M, Fabbrini G, Meco G: Prevalence and clinical features of hedonistic homeostatic dysregulation in Parkinson's disease. Mov Disord 2005, 20:77-8I. 
12. Weintraub D, Siderowf AD, Potenza MN, Goveas J, Morales KH, Duda JE, Moberg PJ, Stern MB: Association of dopamine agonist use with impulse control disorders in Parkinson disease. Arch Neurol 2006, 63:969-73.

13. Evans $A H$, Lawrence AD, Potts J, Appel S, Lees AJ: Factors influencing susceptibility to compulsive dopaminergic drug use in Parkinson disease. Neurology 2005, 65:1570-4.

14. Bearn J, Evans A, Kelleher M, Turner K, Lees A: Recognition of a dopamine replacement therapy dependence syndrome in Parkinson's disease: a pilot study. Drug Alcohol Depend 2004, 76:305-10.

15. Weintraub D, Koester J, Potenza MN, Siderowf AD, Stacy MA, Whetteckey J, Wunderlich GR, Lang AE for the DOMINION Study Group: Dopaminergic therapy and impulse control disorders in Parkinson's disease: a cross-sectional study of over 3,000 patients. Paper presented at: The Movement Disorder Society's 12th International Congress of Parkinson's Disease and Movement Disorders; 22-26 June, 2008, Chicago, IL.

16. Evans AH, Katzenschlager R, Paviour D, O'Sullivan JD, Appel S, Lawrence $A D$, Lees $A J$ : Punding in Parkinson's disease: its relation to the dopamine dysregulation syndrome. Mov Disord 2004, 19:397-405.

17. Friedman JH: Punding on levodopa. Biol Psychiatry 1994, 36:350-I.
18. Fernandez HH, Friedman JH: Punding on L-dopa. Mov Disord 1999, 14:836-8.

19. Miwa H, Kondo $\mathrm{T}$ : Increased writing activity in Parkinson's disease: a punding-like behavior? Parkinsonism Relat Disord 2005, I I:323-5.

20. Potenza MN, Steinberg MA, Skudlarski P, Fulbright RK, Lacadie CM, Wilber MK, Rounsaville BJ, Gore JC, Wexler BE: Gambling urges in pathological gambling: a functional magnetic resonance imaging study. Arch Gen Psychiatry 2003, 60:828-36.

21. Reuter J, Raedler T, Rose M, Hand I, Glascher J, Buchel C: Pathological gambling is linked to reduced activation of the mesolimbic reward system. Nat Neurosci 2005, 8:147-8.

22. Stacy $M$, Galpern $W$, Samuel M, Lang AE: Impulse control disorders in Parkinson's disease. Mov Disord 2008, 23 (Suppl): 1332.

23. Stacy M: Impulse control disorders in Parkinson's disease: criteria for diagnosis. Mov Disord 2008, 23 (Suppl): I34I.

24. Lang AE: Impulse control disorders: future directions. Mov Disord 2008, 23 (Suppl): 1343.

25. Galpern WR, Stacy M: Management of impulse control disorders in Parkinson's disease. Curr Treat Options Neurol 2007, 9:189-97. 